\title{
Cytotoxic Long-chain Alkene and Terpene Isolated from the Methanol Extract of the Air-dried Leaves of Pipturus arborescens C.B. Rob
}

\author{
Charlie A. Lavilla, Jr. ${ }^{1}$, Mylene M. Uy ${ }^{1}$, Shinji Ohta ${ }^{2}$ \\ ${ }^{1}$ Department of Chemistry, College of Science and Mathematics, \\ Mindanao State University-Iligan Institute of Technology, Iligan City, 9200 \\ ${ }^{2}$ Instrument Center for Chemical Analysis, Hiroshima University, 1-3-1 Kagamiyama, \\ Higashi-Hiroshima 739-8526, Japan \\ Corresponding author: Charlie A. Lavilla, Jr., email: ca.lavillajr@yahoo.com
}

\begin{abstract}
A long-chain alkene (1-hexacosene) and a terpene were obtained from the bioactive methanol extract of the air-dried leaves of Pipturus arborescens (Link) C.B. Rob ("Handalamay") collected from Poblacion, Kapatagan, Lanao del Norte. The compounds were isolated through extraction with ethanol, sequential partitioning with water-chloroform and hexane- $90 \%$ methanol followed by fractionation and purification with repeated gravity column chromatography using gradient mixtures of hexane: ethyl acetate (1:1 ratio). The structures of the isolates were elucidated on the basis of spectroscopic data: ${ }^{1} \mathrm{H}$-and ${ }^{13} \mathrm{C}-\mathrm{NMR}$, ${ }^{1} \mathrm{H}^{-13} \mathrm{C}$ Heteronuclear Multiquantum Correlation (HMQC), ${ }^{1} \mathrm{H}-{ }^{13} \mathrm{C}$ Heteronuclear Multibond Correlation (HMBC), ${ }^{1} \mathrm{H}-{ }^{1} \mathrm{H}$ Homonuclear Correlation Spectroscopy (COSY), Infra-Red Spectroscopy (IR), Ultraviolet-Visible Spectroscopy (UV-VIS) and Mass Spectrometry (MS). The isolated compounds were shown to possess moderate cytotoxic activity against the brine shrimp Artemia salina (Leach).
\end{abstract}

Keywords: bioactive, chromatography, fractionation, spectroscopy,1-hexacosene 


\section{Introduction}

Plants have been the basis of many traditional medicine systems throughout the world for thousands of years and continue to provide mankind with new remedies. Organic compounds from terrestrial plants have extensive past and present uses in treatment for many diseases and serve as compounds of interest both in their natural form as well as templates for synthetic modification. The practical use of plants for health care provides a substantial resource in meeting drug requirements. However, the prevalent medicinal use of plants is mostly based on tradition. Thus, the need for scientific validation is invoked.

Pipturus arborescens (Link) C.B. Rob ("Handalamay" in Visayan and "Dalunot" in Tagalog) is a widely distributed species in the Philippines that belongs to family Urticaceae. A recent study reported that methanol extract of certain species belonging to Urticaceae family exhibited cholinesterase inhibitory activity (Dhivya et al., 2014). Another study also showed that the hydroalcoholic extract of a plant under Urticaceae family has hypoglycemic effect and protective activity of beta-cells of Langerhans in hyperglycemic rats (Golalipour et al., 2007). $P$. arborescens is used as a remedy for boils and skin diseases known as Herpes zoster ("ugahip" in Visayan) (Quisumbing, 1978). The scrapings of the bark are used externally as a cataplasm for boils while the leaves are used to cure herpes (Esperanza \& Kitche, 2005). A study reported that triterpenes such as glutinone, friedelin, glutinol, and a mixture of common sterols such as campesterol, stigmasterol and sitosterol have been isolated from the hexane extract of the leaves (Gabona, 2000). Another study also reported that ficaprenol-10 and squalene were also isolated from the methanol extract of $P$. arborescens leaves (Peteros, 2010).

It has also been reported that a pure isolate obtained from the crude ethyl acetate extract of the leaves of $P$. arborescens is active against Bacillus subtilis (Rosal, 1995). A preliminary study revealed that the methanolic extract of the air dried leaves of $P$. arborescens exhibited significant activities against Staphylococcus aureus and Escherichia coli (Enerio, 2007). Thus, the present study was conducted in order to further investigate the possibility on the isolation, purification and identification of the chemical components from the bioactive fraction of air-dried leaves of $P$. arborescens using chromatographic methods, and to elucidate the 
molecular structures through various spectroscopic methods, and finally to determine the cytotoxic activity of the isolates using the Brine Shrimp Lethality assay.

\section{Materials and Methods}

\section{General}

Column chromatography was carried out using silica gel 60 (Merck, 70-230 mesh, ASTM) as an adsorbent. All NMR spectra were recorded on a JEOL AL- 400 (400 MHz- $\left.{ }^{1} \mathrm{H} \mathrm{NMR,} 100 \mathrm{MHz}-{ }^{13} \mathrm{C} \mathrm{NMR}\right)$ spectrometer in $\mathrm{CDCl}_{3}$ solutions using tetramethylsilane (TMS) as an internal standard. MS data were recorded on a Shimadzu LC-MS MALDI-TOF[MS]. UV spectrometric profiles of the isolates were obtained using the Shimadzu 160A UV-Vis Spectrophotometer at the wavelength range of $200-800 \mathrm{~nm}$ with methanol as the reference solvent. The IR spectra were recorded on a Horiba FT-IR 720 spectrometer.

\section{Sampling and Sample Preparation}

Mature leaf samples of $P$. arborescens were collected and obtained from Kapatagan, Lanao del Norte, Philippines. The samples were air-dried for one month, cut into small pieces, ground in a grinder to obtain a fine powder and stored in polyethylene bags at room temperature. Plants were authenticated by Professor Josefa D. Villanueva of the Department of Biological Sciences, College of Science and Mathematics, MSU-Iligan Institute of Technology.

\section{Phytochemical screening}

The ground sample $(1.06 \mathrm{~kg})$ of air-dried leaves was soaked with $95 \%$ ethanol for seven days in the refrigerator at $5^{\circ} \mathrm{C}$. The ethanol extract was then filtered and concentrated under a rotary evaporator at a temperature below $40^{\circ} \mathrm{C}$ to yield $30.99 \mathrm{~g}$ of crude ethanolic extract. The crude ethanol extract was then partitioned between water and chloroform to give the aqueous extract, the chloroform extract and a considerable amount of brick-red solid interphase. A $14.50 \mathrm{~g}$ portion of chloroform extract was subsequently partitioned between hexane and $90 \%$ methanol to give $5.15 \mathrm{~g}$ of hexane extract and $4.91 \mathrm{~g}$ of methanol extract. Methanol was chosen for further study since it has been reported to have the most 
significant antimicrobial activity among the four extracts (Enerio, 2007). Methanol extract was eluted through a silica gel column using gradient mixtures of hexane-ethyl acetate and methanol-ethyl acetate at $10 \%$ increment then $10 \%$ methanol in chloroform and 10\% water in methanol. Thin Layer Chromatography (TLC) was used to characterize and pool the eluted fractions. A sub-fraction from the methanol extract was then further purified through a series of three column chromatography using gradient mixtures of hexane-ethyl acetate to obtain two isolates.

\section{Brine Shrimp Toxicity Assay}

Natural seawater was used as the culture medium. Seawater was boiled for 30 minutes and then filtered to obtain a sterile medium. The medium was poured into the hatching tank and about 100 to $200 \mathrm{mg}$ cysts were introduced. A 100-watt lamp was positioned to provide direct light and warmth throughout the embryogenesis. After 36 hours, the nauplii were collected using Pasteur pipette from the hatching tank and were transferred to a Petri dish with $5.0 \mathrm{~mL}$ of seawater. The assay was carried out according to the principle and protocol previously described by Meyer et al. in 1982 with slight modifications. Ten nauplii were transferred to a sample test tube and sterilized seawater was then added to make a volume of $5.0 \mathrm{~mL}$. A parallel series of tests with the positive control (podophyllotoxin) and a blank control (methanol) was also conducted. There were three replicates in each treatment. Number of survivors and percentage lethality were evaluated after 6 hours and 24 hours.

\section{Results and Discussion}

Two isolates, namely Isolate 1 and Isolate 2 were obtained from the methanol extract of the air-dried leaves of $P$. arborescens. Isolate 1 was obtained as colorless oily liquid yielding only $25.20 \mathrm{mg}$ mass. The ${ }^{1} \mathrm{H}$ and ${ }^{13} \mathrm{C}$ signals for Isolate 1 are summarized in Table 1. Its molecular formula was established to be $\mathrm{C}_{26} \mathrm{H}_{52}$ on the basis of the LC-MS data wherein the compound displayed an ion peak at 365.1 corresponding to $\left[\mathrm{M}^{+}+\mathrm{H}\right]$. The FT-IR spectrum obtained on thin film exhibited absorption bands at 3077.83, 2923.56, 2854.13 $\mathrm{cm}^{-1}\left(\mathrm{sp}^{2}-\mathrm{CH}\right.$ and $\mathrm{sp}^{3}-\mathrm{CH}$ stretching) and 1639.20-1720.19 $\mathrm{cm}^{-1}(\mathrm{C}=\mathrm{C}$ stretching). The UV spectrum showed the absorption maximum at $211 \mathrm{~nm}$ characteristic of an alkene system. 
The ${ }^{13} \mathrm{C}$ NMR and ${ }^{13} \mathrm{C}$ DEPT spectra showed the presence of an olefinic terminal methylene carbon $(\delta 114.0 \mathrm{ppm})$, an olefinic methine carbon ( $\delta 139.2 \mathrm{ppm}$ ), a cluster of methylene carbons ( $\delta 22.8-33.9 \mathrm{ppm})$ and a methyl carbon $(\delta 14.2 \mathrm{ppm})$. The ${ }^{1} \mathrm{H}-\mathrm{NMR}$ spectrum displayed a signal at $\delta 5.81 \mathrm{ppm}$ attributed to the olefinic methine proton. The doublet of doublets signals at $\delta 4.99 \mathrm{ppm}\left(J_{11}=17.2,1.4 \mathrm{~Hz}\right)$ and at $\delta 4.92 \mathrm{ppm}$ $\left(J_{11}=10.3,1.4 \mathrm{~Hz}\right)$, are assigned to the terminal olefinic methylene protons. The signal at $\delta 2.04 \mathrm{ppm}$ is due to the methylene protons next to the olefinic methine proton. The broad signals at $\delta 1.26-\delta 1.37 \mathrm{ppm}$ are typical of internal methylene protons while the triplet $(J=3.0 \mathrm{~Hz})$ signal at $\delta 0.88$ corresponds to the lone methyl protons.

Table 1. ${ }^{1} \mathrm{H}$-and ${ }^{13} \mathrm{C}$-NMR Data of Isolate 1.

\begin{tabular}{cccc}
\hline \hline Position No. & $\boldsymbol{\delta}^{\mathbf{1}} \mathbf{H}^{\mathbf{a}}, \mathbf{p p m}$ & Multiplicity $(\boldsymbol{J}$ in $\boldsymbol{H z})$ & $\boldsymbol{\delta}^{\mathbf{1 3}} \mathbf{C}^{\mathbf{b}}, \mathbf{p p m}$ \\
\hline 1 & 4.99 & $\mathrm{dd}(17.2,1.4)$ & 114 \\
2 & 4.92 & $\mathrm{dd}(10.3,1.4)$ & 139.2 \\
3 & 5.81 & $\mathrm{~m}$ & 33.9 \\
4 & 2.04 & $\mathrm{~m}$ & $22.8-32.0$ \\
5 & $1.26-1.37$ & broad $\mathrm{m}$ & 14.2 \\
\hline \hline
\end{tabular}

${ }^{\mathrm{a}}$ Data measured in $\mathrm{CDCl}_{3}$ at $400 \mathrm{MHz}$.

${ }^{\text {b}}$ Data measured in $\mathrm{CDCl}_{3}$ at $100 \mathrm{MHz}$.

In the COSY spectrum, the terminal olefinic methylene protons $(\delta 4.99,4.92)$ were coupled to the olefinic methine proton at $\delta 5.81$ which in turn showed coupling with the methylene signal at $\delta 2.04$. The methylene protons at $\delta 2.04$ then coupled with the broad methylene peaks at $\delta$ 1.26-1.37 which showed coupling with the methyl protons $(\delta 0.88)$. With the corroboration of the LC-MS, IR, UV, and NMR data, the structure of Isolate 1 could be proposed as 1-hexacosene (Figure 1).

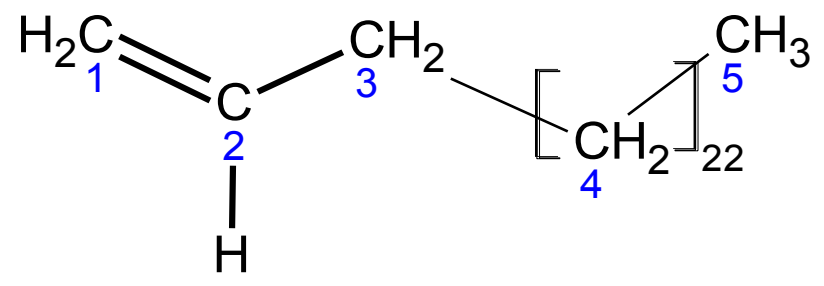

COSY

Figure 1. Proposed structure of Isolate 1 (1-hexacosene). 
Isolate 2 was obtained as light orange oil which gave a lighter pink color under UV lamp and brown color upon exposure to iodine vapor. It yielded $40.20 \mathrm{mg}$ of the product. The ${ }^{1} \mathrm{H}$-and ${ }^{13} \mathrm{C}-\mathrm{NMR}$ Data of Isolate 2 are summarized in Table 2. The FT-IR spectrum of Isolate 2 obtained on thin film showed absorption bands at 2726.85-2958.27 $\mathrm{cm}^{-1}$ ( $\mathrm{sp}^{2}$ and $\mathrm{sp}^{3} \mathrm{C}-\mathrm{H}$ stretch), 1373.07-1454.06 (C-H bending of a methyl group), and 1592.91-1668.12 ( $\mathrm{C}=\mathrm{C}$ stretching). The UV spectrum displayed absorption maxima at 212, 254 and $284 \mathrm{~nm}$ indicating the presence of a polyene system. The ${ }^{13} \mathrm{C}-\mathrm{NMR}$ spectrum indicated the presence of quaternary carbons $(\delta 131.1,135.2 \mathrm{ppm})$, olefinic methine carbons $(\delta 124.1,124.3,124.4,124.8,124.9$ ppm), methyl carbons ( $\delta 16.2,17.8,22.8,23.3,23.4,25.7,26.6 \mathrm{ppm}$ ), methylene carbons ( $\delta 24.9,25.8,26.4,26.5,26.8,32.1,32.3,39.8 \mathrm{ppm}$ ) and terminal methine carbon $(\delta 17.8 \mathrm{ppm})$. In the COSY spectrum, the olefinic methine proton at $\delta 5.11 \mathrm{ppm}$ was coupled to the methylene protons at $\delta 2.0-2.1 \mathrm{ppm}$ which in turn showed coupling to the methyl protons at $\delta 1.60,1.68,1.74$ ppm. The methylene protons also showed another coupling to the terminal methine proton at $\delta 1.56 \mathrm{ppm}$ which displayed coupling to the methyl protons at $\delta 1.28$ and $0.86 \mathrm{ppm}$.

Table 2. ${ }^{1} \mathrm{H}$-and ${ }^{13} \mathrm{C}$-NMR Data of Isolate 2.

\begin{tabular}{ccc}
\hline \hline Position Number & $\boldsymbol{\delta}^{\mathbf{1}} \mathbf{H}^{\mathbf{a}}, \mathbf{p p m}$ & $\boldsymbol{\delta}^{\mathbf{1 3}} \mathbf{C}^{\mathbf{b}}, \mathbf{p p m}$ \\
\hline 1 & 1.56 & 17.8 \\
2 & $2.04-2.16$ & $32.1-32.3$ \\
3,7 & 5.11 & $124.1-124.4$ \\
4 & - & $131.1-135.2$ \\
5 & $2.04-2.16$ & 39.8 \\
6 & $2.04-2.16$ & 26.8 \\
8 & - & 131.11 \\
9 & 1.68 & 25.7 \\
10 & 1.28 & 26.6 \\
11 & 0.86 & 22.8 \\
12 & 1.6 & 16.2 \\
13 & 1.6 & 17.8 \\
\hline \hline
\end{tabular}

${ }^{\mathrm{a}}$ Data measured in $\mathrm{CDCl}_{3}$ at $400 \mathrm{MHz}$

${ }^{\mathrm{b}}$ Data measured in $\mathrm{CDCl}_{3}$ at $100 \mathrm{MHz}$ 
The HMQC and the HMBC correlations, made possible the assignment of the chemical shifts of protons directly attached and correlated two to three bonds away, respectively to a given carbon atom. The proton signal at $\delta 1.68 \mathrm{ppm}$ is correlated two bonds away to the quaternary carbons $(\delta 131.1,135.2 \mathrm{ppm})$ and to the olefinic methane carbons $(\delta 124.1,124.3,124.4 \mathrm{ppm})$. This proton signal is also correlated three bonds away to the methylene carbons at $\delta 32.3 \mathrm{ppm}$. The methyl proton at $\delta 1.60 \mathrm{ppm}$ displayed a correlation with the quaternary carbon at $\delta 135.2 \mathrm{ppm}$. Meanwhile, the methylene protons ( $\delta 2.0-2.1 \mathrm{ppm})$ exhibited correlation to the olefinic methine carbons ( $\delta 124.1,124.3,124.4 \mathrm{ppm})$, to the quaternary carbons two and three bonds away $(\delta 131.1,135.2 \mathrm{ppm})$ respectively, and to the methylene carbons ( $\delta 32.1,32.3,39.8 \mathrm{ppm})$. The terminal methyl protons $(\delta 1.28,0.86 \mathrm{ppm})$ are correlated to the methylene carbon at $\delta 32.3 \mathrm{ppm}$. Furthermore, the methyl protons at $\delta 0.86$ also showed a correlation to the terminal methyl carbon at $\delta 26.6 \mathrm{ppm}$. The important confirmation regarding the mass of the molecular ions and hence the exact molecular weight of Isolate 2 could not be established as there is no available mass spectral data. However, on the basis of IR, UV, and NMR data, the structure of Isolate 2 could be proposed as a terpene (Figure 2).

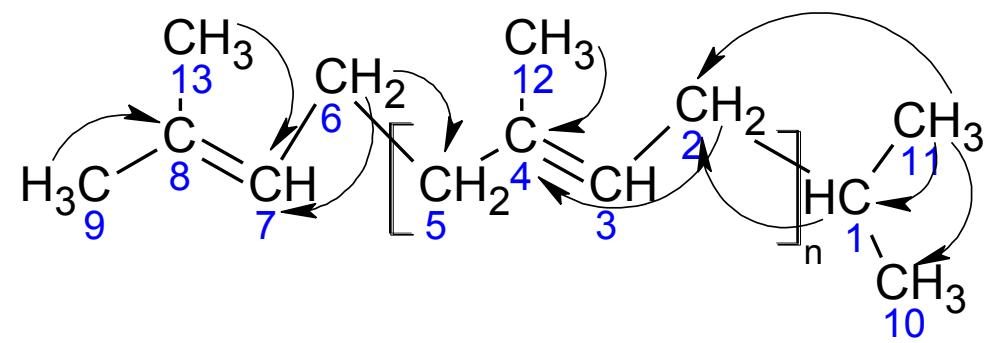

Figure 2. Proposed structure of Isolate 2 (Terpene).

The $\mathrm{LC}_{50}$ of Isolate 1 was not determined as the amount of the compound extracted was not sufficient enough to conduct the experiment. However, its cytotoxicity was evaluated by determining percent mortality rate at $1000 \mathrm{ppm}$ concentration, and was found to be $40.00 \%$. The mortality of brine shrimp assay in Isolate 2 is given in Table 3. 
Table 3. Mortality of the brine shrimp larvae after $24 \mathrm{~h}$ of exposure to Isolate 2.

\begin{tabular}{cc}
\hline \hline Concentration (ppm) & Mortality (\%) \\
\hline 10.0 & 0.00 \\
100.0 & 10.20 \\
1000.0 & 45.71 \\
\hline \hline
\end{tabular}

The results indicate that Isolate 2 exhibits the mortality of $45.71 \%$ against the test animal at $1000.0 \mathrm{ppm}$, significantly low activity $(10.2 \%)$ at $100.0 \mathrm{ppm}$ and no activity at all at low concentrations such as $10.0 \mathrm{ppm}$. In the estimation of $\mathrm{LC}_{50}$ using Probit analysis (Finney, 1971), it could be suggested that, Isolate 2 has $\mathrm{LC}_{50}$ of $2344.23 \mathrm{ppm}$ with a standard error of 1.74 at $95 \%$ confidence level, thus the range could be suggested as 2340.75-2347.71 ppm. The BSLT assay has proven to be a convenient system for screening bioactive natural products. It has the complete and effective range to test the toxicity as well as for various assays (Kanwar, 2007). The brine shrimp lethality assay represents a rapid, inexpensive and simple bioassay for testing plant extracts bioactivity which in most cases correlates reasonably well with cytotoxic and anti-tumor properties (McLauglin et al., 1993). The cytotoxicity of Isolate 2 provides baseline information that this is possible for clinical use indicative of anticancer, antiviral and other wide-range of pharmacological activities (Sayeed et al., 2003). The exact mechanism of cytotoxic action of any tested isolates is not yet known; it is simply provided by disturbing the fundamental mechanisms concerned with cell growth, mitotic activity, differentiation and function (Goodman et al., 1980). However, to better evaluate the potential cytotoxic effectiveness of Isolate 2 from the leaves of $P$. arborescens, it warrants further investigation and specific studies.

\section{Conclusion and Recommendation}

The bioactive methanol extract of the air-dried leaves of Pipturus arborescens (Link) C.B. Rob ("Handalamay") afforded a long-chain alkene and a terpene through repeated gravity column chromatography. The isolated compounds exhibited moderate toxicity towards the brine shrimp and it can be inferred that the isolated compounds are biologically 
active. With more advanced chromatographic techniques, there are certainly many compounds with interesting activities yet to be discovered from $P$. arborescens. Extracts, fractions and the isolated compounds should be subjected to as wide a range of bioassays as possible in order to confirm this conclusion.

\section{Acknowledgment}

Measurements of IR, MS and NMR data were conducted in Japan through Dr. Shinji Ohta of Nagahama Institute of Bio-Science and Technology; Jomarie P. Enerio for providing the plant samples; Prof. J. D. Villanueva for the identification of the plant materials; Department of Science and Technology for the financial support; and Mindanao State University - Iligan Institute of Technology.

\section{Literature Cited}

Dhivya, P. S., Sobiya, M., Selvamani, P., \& Latha, S. (2014). An approach to Alzheimer's disease treatment with cholinesterase inhibitory activity from various plant species. International Journal of PharmTech Research, 6(5), 1450-1467.

Enerio, J. P. (2007). Bioassay-guided partial isolation of the antimicrobial components from the leaves of Pipturus arborescens [Unpublished MS Thesis]. MSU-Iligan Institute of Technology, Iligan City, Philippines.

Esperanza, L. M., \& Kitche, G. O. (2005). Inventory of medicinal tree species in the secondary growth forest of Sitio Tagkiling, Anticala, Butuan City as utilized by the locals. Paper presented at 2005 NORMISIST Research and Development In-House Review, Northern Mindanao State of Science and Technology, Butuan City, Philippines.

Finney, D. J. (1971). Probit Analysis (2nd ed.). New York, NY: Cambridge University Press. 
Gabona, M. (2000). Triterpenoids and other metabolites from the hexane extract of Pipturus arborescens. [Unpublished MS Thesis]. De La Salle University, Manila.

Golalipour, M. J., \& Khori, V. (2007). The protective activity of Urtica dioica leaves on blood glucose concentration and beta-cells in streptozotocin-diabetic rats. Pakistan Journal of Biological Sciences: PJBS, 10(8), 1200-1204.

Goodman, L. S., Gilman, A. G., \& Gilman, A. (1980). Antiproliferative agents and immunosuppressive drugs. The pharmacological basis of therapeutics (6th ed.). USA: Mcmillan Publishing Co., Inc.

Kanwar, A. S. (2007). Brine shrimp (Artemia Salina) - A marine animal for simple and rapid biological assays. Journal of Chinese Clinical Medicine, 2(4), 236-240.

McLauglin, J. L., Chang, C. J., \& Smith, D. L. (1993). Simple bench-top bioassays (brine shrimp and potato discs) for the discovery of plant antitumour compounds. In ACS symposium (Vol. 534, pp. 112137).

Meyer, B. N., Ferrigni, N. R., Putnam, J. E., Jacobsen, L. B., Nichols, D. J., \& McLaughlin, J. L. (1982). Brine shrimp: A convenient general bioassay for active plant constituents. Planta Medica, 45(05), 31-34. doi: 10.1055/s-2007-971236

Peteros, N. P. (2010). Studies on the structures and bioactivities of components of selected Philippine medicinal plants (Unpublished Ph.D. Dissertation]. MSU-Iligan Institute of Technology, Iligan City, Philippines.

Quisumbing, E. (1978). Medicinal Plants of the Philippines. Quezon City: Katha Publishing Co., Inc., JMC Press, Inc. 
Rosal, R. R. (1995). Bioassay-guided isolation and structure elucidation of some metabolites from Pipturus arborescens (Unpublished MS Thesis). De LaSalle University, Manila, Philippines.

Sayeed, A. I. A., Islam, M. A. U., Khan, G. R. M. A. M., \& Bhuiyan, M. S. A. (2003). Brine shrimp lethality bioassay of three terpenes isolated from the bark of Zanthoxylum budrunga wall: A cytotoxic evaluation of plant bioactive principles. Pakistan Journal of Pharmacology, 20(1), 1-5. 